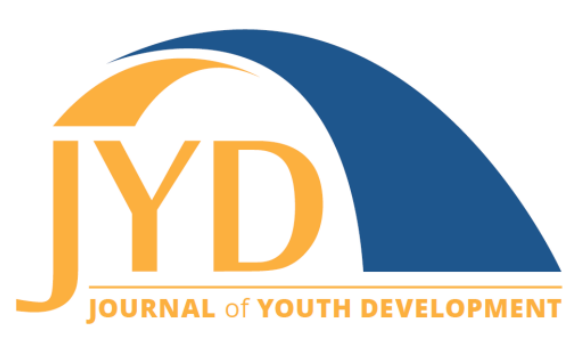

http://jyd.pitt.edu/ | Vol. 15 Issue 4 DOI 10.5195/jyd.2020.986 | ISSN 2325-4017 (online)

\title{
Supporting Volunteerism in Youth Development Programs: Progress and Prospects for Advancing the Knowledge Base
}

\author{
David L. DuBois \\ School of Public Health and Institute for Health Research and Policy, University of Illinois Chicago \\ dldubois@uic.edu
}

\begin{abstract}
Volunteers are essential to the viability of a large segment of youth development programs. Yet, research on this topic has been relatively limited and it has not thus far congealed into a cohesive area of study. The contributions to this special issue advance our understanding of a number of important issues having to do with volunteerism in youth programs and provide a solid foundation for catalyzing both the further generation of knowledge in this area and its practical application. One priority should be to more rigorously establish and delineate suggested connections among program practices, volunteer skill development, behaviors, and experiences, and the outcomes of participating youth. There also is a need to substantially broaden the scope of programs studied in order to clarify both areas of generalizability and dynamics that may vary as a function of volunteer contexts and roles. Finally, as the knowledge base matures, translational research is needed to apply this knowledge to the design of supports for volunteerism in youth development programs and to rigorously evaluate the effectiveness of these strategies.
\end{abstract}

Key words: volunteerism, youth development, program evaluation

\section{Progress and Prospects for Advancing the Knowledge Base}

The articles that comprise this special issue of the Journal of Youth Development on volunteerism in youth development programs, collectively, constitute a significant step forward in advancing the knowledge base on this topic. It is widely appreciated that volunteers are essential to the viability of a large segment of youth development programs and, by implication, their ability to achieve their core mission of enabling young persons to realize their full

\footnotetext{
(cc) EY New articles in this journal are licensed under a Creative Commons Attribution 4.0 License.
} This journal is published by the University Library System, University of Pittsburgh and is cosponsored by the University of Pittsburgh Press. The Journal of Youth Development is the official peer-reviewed publication of the National Association of Extension 4-H Youth Development Professionals and the National AfterSchool Association. 


\section{Supporting Volunteerism in Youth Development}

potential, in effect sowing the seeds for the future health and prosperity of the communities and broader society in which these programs are embedded. With this much at stake one might expect there to be a large body of research that explores volunteerism in youth development programs and how best to support it in ways that allow programs to grow in both scale and effectiveness. Yet, in reality, this remains a largely nascent area of scholarship, dwarfed in scope by those that exist on related topics, such as risk and protective factors for positive youth development and the education and training of teachers, counselors, and other professionals who work with young persons. These and other more established literatures benefit from what have been described as invisible colleges (Crane, 1972) -networks of scholars exchanging ideas and findings with each other on a given topic through both formal and informal channels, thereby cultivating the kinds of cross-fertilization, synergy, and debate that are integral to scientific advancement. A robust invisible college is at present clearly lacking for research on volunteerism in youth development programs. Yet, this special issue, by providing what may well be the first organized collection of scholarly contributions on the topic, lays important groundwork that could, if capitalized on effectively, support the emergence of a more sustained and integrative body of research on volunteerism within youth-serving programs.

This conclusion begs this important question: What types of research will best advance existing knowledge concerning volunteerism in youth programs and catalyze its maturation as a field of inquiry? Taken as representative of current work, the contents of this special issue point toward a need for research that (a) more rigorously establishes and better elucidates connections among program practices for engaging and supporting volunteers, volunteer skills, behaviors, and experiences within programs, and youth outcomes; (b) broadens the scope of programs studied to clarify both areas of generalizability and dynamics that may be specific to particular volunteer contexts and roles; and (c) designs and iteratively refines supports for volunteerism in youth development programs in tandem with well-controlled tests of the effectiveness of these approaches and, where warranted, strategies for their dissemination and scale-up. The remainder of my commentary considers each of these three sets of concerns. In doing so, I endeavor to strike an appropriate balance between highlighting strengths of the current contributions and delineating next steps that are needed to build strategically on this work in service of advancing the knowledge base for volunteerism in youth programs and its effective translation to practice. 


\section{Program Engagement and Support Practices, Volunteer Skills, Behaviors, and Experiences, and Youth Outcomes}

Several studies in this special issue report findings that bear on the ways in which the practices that programs utilize to engage and support volunteers may have implications for their skill development, success in carrying out assigned roles, and overall experiences within youth development programs. Reporting on a survey of 4-H volunteers, Hensley and colleagues (2020) find that those who reported having participated in an orientation training rated their competencies as higher in several areas expected to be important for facilitating desired youth outcomes than did volunteers who had not had the orientation training; similar associations were found between self-rated competencies and the total amount of training that volunteers reported having received. Moving outside of $4-\mathrm{H}$ to formal mentoring programs, Keller and colleagues (2020) find significant upticks in volunteers' ratings of their service experience both when comparing those who reported any monitoring and support contacts from staff to those who did not and, interestingly, also when comparing those with the shortest staff contacts (5 minutes or less) to those who reported contacts of longer duration.

These and other similar results contained in the special issue provide valuable insights into how various practices to support volunteers may have important consequences for both their skill development and the overall quality of their experiences within youth development programs. Yet, keeping in mind the axiom that correlation does not prove causation, such findings fall well short of persuasive evidence that the practices involved are indeed influential for the outcomes examined. Consider, for example, that volunteers who self-select into training opportunities in a youth development organization already may tend be relatively more competent. To the extent that this is the case, greater competence may tend to lead to receiving more training rather than vice-versa. Likewise, volunteer mentors who are more satisfied with their experience in a program may have greater amenability to engaging in extended conversations with supervising staff, such that satisfaction drives the length of support contacts rather the other way around. Future research can begin to address these types of possibilities by utilizing longitudinal designs in which program supports and volunteer outcomes of interest are assessed on multiple occasions over time. Such studies could examine, for example, whether receiving different types and amounts of training is associated with increases in volunteer competence from levels that pre-date the training. Although by no means commonplace, studies employing this type of design can be found in the broader literature on volunteer supports within youth development programs. Illustratively, Anderson and colleagues (2018) found that volunteer mentors for Black youth and young men who participated in a social justice training reported increased levels of 


\section{Supporting Volunteerism in Youth Development}

cultural sensitivity and sociopolitical understanding (e.g., bias awareness) in comparison to pretraining levels. Ideally, too, future studies will move beyond sole reliance on volunteer selfreports to include additional sources of data. Prime candidates include program records and the reports of other informants such as professional staff or participating youth. In an investigation of formal youth mentoring programs that employed these types of data, Herrera and colleagues (2013) found that volunteers who had received training early in their relationships according to program records were rated significantly more favorably by their youth mentees with respect to desired behaviors such as engaging with them in learning projects (growth orientation) and actively taking into account their personal needs and preferences (youth-centeredness). Integrating the collection of longitudinal, multi-source data into routine program practice would be especially helpful. Within a national youth-serving organization such as $4-\mathrm{H}$, these data could enhance opportunities for organizational learning regarding best practices for supporting volunteers, provide local clubs with the information needed to gauge applicability of findings to their programs and volunteers, and offer an attractive starting point for researchers interested in collaboration.

A number of findings reported in the special issue studies are also in line with the assumption that volunteers, through their interactions with youth, can enhance their development and future life outcomes. In perhaps the most prominent example of this, Grant and colleagues (2020) found that nearly all of the 4-H volunteers in their sample reported having helped youth increase their skills in the areas of leadership (98\%) and decision-making (97\%) as well as their readiness for future careers (96\%). In a qualitative examination of $4-\mathrm{H}$ volunteers' responses to open-ended survey questions, Worker and colleagues (2020) similarly found several themes of perceived contribution to the positive development of participating youth. Here again, the findings are encouraging, but do not provide a strong basis for concluding that the volunteers in these studies were a positive influence on the outcomes of the youth involved. Research in this area is thus similarly ripe for greater use of rigorous methodologies for establishing cause and effect (e.g., longitudinal designs) as well as the institutionalization of data systems to facilitate large-scale collection of pertinent data (e.g., measures of youth outcomes).

Future studies are also likely to benefit from incorporating more differentiated and nuanced assessments of volunteer behavior. In research on youth mentoring programs, for example, evidence points to the importance of volunteer mentors being able to demonstrate attunement and flexibility in responding to the individual preferences and interests of their mentees (Keller, 2005; Pryce, 2012; Spencer et al., 2020), while at the same time being able to provide more 


\section{Supporting Volunteerism in Youth Development}

structured guidance that facilitates the youth's growth and attainment of valued goals (Hamilton \& Hamilton, 2004; Langhout et al., 2004). Many volunteers, despite the best of intentions, fall short of realizing this ideal in one direction or the other, leaving youth less well positioned to benefit from their mentoring relationships (Keller, 2005). Related research has revealed that adult facilitators in youth programs routinely encounter a range of dilemmas of practice (Larson \& Walker, 2010)—situations that require addressing multiple, often competing considerations (e.g., a goal of facilitating youths' learning yet wanting the initiative for this learning to come from them), the handling of which can be turning points in a program's effectiveness in facilitating youth development. Future investigations could build on the foregoing lines of research literature to examine how volunteers in youth development programs navigate different types of challenging situations in their roles and the attendant implications for the nature and extent of the benefits that youth derive from their participation.

\section{Broadening the Programmatic Scope of Investigations}

Eight of the 11 studies in this special issue focus on 4-H programs. The remaining three are centered on programs in which volunteers provide one-to-one mentoring or tutoring to youth. Notwithstanding the differing roles and responsibilities of volunteers in the two types of programs, points of commonality can be discerned in the findings and conclusions of the respective sets of studies. One of the most notable of these is the importance of providing volunteers with not only initial training, but also ongoing support that is both timely and relevant throughout their involvement with the organization. In their mixed method study of volunteer education and support within 4-H programs, White and colleagues (2020) found that respondents frequently expressed a need for "information and educational resources that are timely, relevant, and easily accessible" (p. 123). Similarly, in their analysis of the READ718 tutoring program, Restler and Glant (2020) observed that "volunteers learn most when they get substantive support in real time when engaging with a specific student on a specific issue" ( $p$. 169). In line with these findings, my colleagues and I (DuBois et al., 2002) found in a metaanalysis of evaluations of youth mentoring programs that training provided after mentoring relationships had begun was predictive of greater effectiveness, whereas this was not the case for pre-service training. More recently, researcher Sam McQuillin (2018) gave this account of the benefits of incorporating ongoing training in a school-based mentoring program that he and his colleagues have developed:

We would corral mentors in a room and teach them until they were exhausted, and then we'd hope and pray that they would remember in the months following 
Supporting Volunteerism in Youth Development

after they first met and then mentored their mentees. Not surprising in hindsight, we found that they didn't do the things we taught them to do, and they did many of the things we taught them not to do.

We later revised our training to emphasize briefer trainings spread out throughout the course of the mentoring relationship. This ongoing training would rehash things learned in the upfront trainings using examples relevant to mentors' match, and other trainings would introduce concepts that might only be relevant for one or two meetings. In subsequent evaluations of our program, we noticed remarkable improvements in mentors' appreciation of the program and training, and in the effects of the program on students' outcomes. (paras. 3-4)

Future research should seek to further elucidate commonalities in potential best practices for supporting volunteers in youth development programs. Comparative studies that encompass diverse types of programs and volunteer roles may be particularly informative for this purpose.

Expanding the scope of the programmatic contexts that is examined will also inevitably reveal differences in volunteer motivations; useful practices for recruiting, supporting, and retaining volunteers; volunteer characteristics and behaviors that are most conducive to promoting desired youth outcomes; and so on. Notably absent from the program contexts examined in the special issue are prominent national youth development organizations other than $4-\mathrm{H}$ that are also heavily dependent on volunteers, such as Scouts and Camp Fire, as well as programs of this type that tend to be locally-situated, such as those associated with youth sports and religious organizations. Also lacking representation are those in which volunteers have less prominent roles, but frequently are present and involved in direct interactions with youth, such as YMCAs, Boys \& Girls Clubs, and camp settings. Noteworthy in this regard is the manner in which Restler and Glant (2020) place the role of volunteers in organizations on a continuum, with volunteer-dependent organizations (i.e., those in which volunteers "are the vital backbone of service delivery, without whom the organizations would be hard-pressed to exist" [p. 162]) at one end and those in which staff deliver all services and volunteers assume only minor and episodic roles at the other. These authors call particular attention to programs in the middle of this continuum that employ what they refer as a "value-add" model of volunteerism (i.e., volunteers, although not essential to the program, have the potential to expand services to youth in ways that otherwise would not be possible). Their analysis highlights several factors that may be particular challenges for mounting sustained and effective volunteer programs in 


\section{Supporting Volunteerism in Youth Development}

such organizations (e.g., insufficient resources devoted to managing the program, friction between paid staff and volunteers), coupled with recommended practices for minimizing these risks (e.g., ensuring that the volunteer program has the buy-in of both organizational leadership and paid staff). Future research could benefit greatly from the application of similarly purposed organizing frameworks. Such frameworks could help bring order to what otherwise has the potential to become a fragmented and poorly integrated literature and one that is prone to silos of research focused on specific programs.

\section{Designing, Testing, and Scaling up Effective Supports for Volunteerism in Youth Development Programs}

Research on a topic such as volunteerism in youth development programs is arguably only as useful as the extent to which it results in improved practice. There is both good news and notso-good news here with respect to the contributions to this special issue. The good news is that the contributions are rich in findings that suggest promising directions for strengthening program practices. The authors, moreover, uniformly do an excellent job of calling out these possibilities. Illustratively, based on focus groups and interviews conducted with youth, parents, volunteers, and paid staff in 4-H STEM programs, Franck and Donaldson (2020) suggest a twofold need both for non-scientist volunteers to receive training focused on bolstering their STEM knowledge and skills and for those who do have STEM expertise to be supported in developing effective skills for pedagogy and youth engagement. Kok and colleagues (2020) similarly identify $4-\mathrm{H}$ volunteer training needs in the areas of project-specific subject matter and child development as well as program management fundamentals. Further findings from this study highlight preferred approaches for skill learning and professional development among volunteers, with peer-to-peer learning and online formats leading the list, the latter result being in line with Homan and colleagues (2020) identifying a preference for more self-directed forms of training among 4-H volunteers. Outside of 4-H, Miranda-Díaz and colleagues (2020) find that ethnocultural empathy, a potential indicator of ability to connect with youth across cultural differences, was a predictor of altruistic, but not self-oriented motivations to volunteer. These authors suggest that programs consider taking steps to gather data about volunteer motivations, being mindful of their potential associations with desired attributes of mentors. With potential broad relevance to supporting and retaining volunteers in youth development programs, Morris (2020) calls attention to different "languages" or modes of showing appreciation to volunteers (e.g., words of affirmation, acts of service that help volunteers fulfill 


\section{Supporting Volunteerism in Youth Development}

their roles). She points to the potential value of identifying each volunteer's preferred "language" and tailoring recognition of their contributions accordingly.

The not-so-good news is that none of the studies in the special issue tackle the critical next steps in the process of translating research to practice. These steps include developing modified or new practices that are informed by research findings such as those described above, conducting formative studies to ensure that innovations as designed are feasible to implement and acceptable to all stakeholders, and rigorously evaluating their effectiveness to determine if they are beneficial in ways that are anticipated. Only after having progressed through all of these phases of activity, with favorable results, should attention turn to investments in scale-up of innovations and institutionalizing them for permanent use within the host organization. Undertaking such an extended process might well seem unduly onerous and of questionable necessity, especially for practices that are broadly informed by research and often also have strong intuitive appeal. The importance of a multistep development and evaluation process becomes clear, however, when considering the results of several recent investigations that have examined the feasibility and benefits of incorporating additional supports for volunteers who serve as mentors to youth in programs such Big Brothers Big Sisters. A recurring feature of these studies is the introduction of additional training for volunteers prior to and/or after being paired with their mentees; this training typically has had the aim of equipping mentors to engage in activities with their mentees that are directed toward specific goals such as promoting indicators of thriving (e.g., a growth mindset; DuBois \& Keller, 2017) or academic success and college attendance (Brezina et al., 2016). Several of these evaluations having been quite sizable in scope, involving hundreds of mentors and youth from multiple program sites. Yet, their results as a whole have provided very limited evidence that the new practices resulted in improved youth outcomes (for a review, see DuBois et al., 2018). Implementation challenges, such as problematically low rates of mentor attendance at trainings and frequent premature endings of mentoring relationships, have been a consistent theme across the projects. Such findings underscore the importance of field testing and refining innovations prior to investing in costly and demanding outcome evaluations.

Although less commonly attempted, the results of efforts to integrate and evaluate innovations in other volunteer-dependent organizations such as 4-H also suggest a need for caution (see, e.g., Trzesniewski et al., 2015). Those looking to translate findings such as those reported in this special issue into improved support for volunteerism in youth development programs are thus advised to embrace an incremental and iterative process of innovation, testing, and 
refinement, similar to that evident in the previously described work of McQuillin and colleagues (2018). In doing so, special attention should be given to fitting innovations to the prevailing motivations, skill profiles, and time and other situational constraints of the volunteers involved, especially as compared to paid professional staff (DuBois \& Keller, 2017).

\section{Concluding Comments}

At the outset of this commentary I suggested the value of cultivating an invisible college for research on volunteerism in youth development programs. The editors of this special issue should be commended for spearheading a valuable first step toward this goal, as should the authors for their robust and thoughtful contributions to the final product. Although by no means a finished task, the groundwork clearly has been laid for research on volunteerism in youth development programs to gain momentum and more fully realize its promise of strengthening the capacity and effectiveness of these vitally important organizations.

\section{References}

Anderson, A. J., Sánchez, B., Meyer, G., \& Sales, B. (2018). Supporting adults to support youth: An evaluation of two social justice trainings. Journal of Community Psychology, 46(8), 1092-1106. https://doi.org/10.1002/jcop.22093

Brezina, T., Kuperminc, G., \& Tekin, E. (2016). Future selves, motivational capital, and mentoring toward college: Assessing the impact of an enhanced mentoring program for at-risk youth. Grant Number: 2012-50614-GA-JU. Final Technical Report. https://www.ncjrs.gov/pdffiles1/ojjdp/grants/250499.pdf

Crane D. (1972). Invisible colleges: Diffusion of knowledge in scientific communities. University of Chicago Press.

DuBois, D. L., Alem, F., \& Silverthorn, N. (2018). Synthesis of OJJDP-sponsored mentoring research. NCJ 252166. https://www.ncjrs.gov/pdffiles1/ojjdp/grants/252166.pdf

DuBois, D. L., Holloway, B. E., Valentine, J. C., \& Cooper, H. (2002). Effectiveness of mentoring programs for youth: A meta-analytic review. American Journal of Community Psychology, 30(2), 157-197. https://doi.org/10.1023/A:1014628810714

DuBois, D. L., \& Keller, T. E. (2017). Investigation of the integration of supports for youth thriving into a community-based mentoring program. Child Development, 88(5), 1480-1491.

\section{https://doi.org:10.1111/cdev.12887}


Franck, K. L., \& Donaldson, J. L. (2020). Volunteer training needs for successful 4-H STEM programs. Journal of Youth Development, 15(4), 97-109. https://doi.org/10.5195/jyd.2020.856

Grant, S., Maass, S., Vettern, R., Harrington, R., O'Neil, K., McGlaughlin, P., \& Good, T. (2020). The impact of volunteering: A multi-state study of $4-\mathrm{H}$ youth development volunteers. Journal of Youth Development, 15(4), 32-50. https://doi.org/10.5195/jyd.2020.870

Hamilton, S. F., \& Hamilton, M. A. (2004). Contexts for mentoring: Adolescent-adult relationships in workplaces and communities. In R. M. Lerner \& L. Steinberg (Eds.), Handbook of adolescent psychology (pp. 395-428). Wiley.

Hensley, S. T., Kent, H. C., Broaddus, B. A., Ellison, S., Michael, S. T., \& Spero, V. (2020). 4-H volunteer attainment of quality positive youth development practices. Journal of Youth Development, 15(4), 87-96. https://doi.org/10.5195/jyd.2020.882

Herrera, C., DuBois, D. L., \& Grossman, J. B. (2013). The role of risk: Mentoring experiences and outcomes for youth with varying risk profiles. A Public/Private Ventures project published by MDRC. http://www.mdrc.org/sites/default/files/Role\%20of\%20Risk Exec\%20Sumweb\%20final.pdf

Homan, D., Epley, H. K., \& Bloir, K. L. (2020). Are volunteers competent in positive youth development? Perceptions from three stakeholder groups. Journal of Youth Development, 15(4), 68-86. https://doi.org/10.5195/jyd.2020.742

Keller, T. E. (2005). The stages and development of mentoring relationships. In D. L. DuBois, \& M. J. Karcher, (Eds.), Handbook of youth mentoring (pp. 82-99). SAGE.

Keller, T. E., Drew, A. L., Clark-Shim, H., Spencer, R., \& Herrera, C. (2020). It's about time: Staff support contacts and mentor volunteer experiences. Journal of Youth Development, 15(4), 145-161. https://doi.org/10.5195/jyd.2020.879

Kok, C. M., Espinoza, D. M., Worker, S. M., Go, C., \& Miller, J. C. (2020). Identification of priority skill areas for volunteer professional development. Journal of Youth Development, 15(4), 51-67. https://doi.org/10.5195/jyd.2020.876

Langhout, R. D., Rhodes, J. E., \& Osborne, L. N. (2004). An exploratory study of youth mentoring in an urban con- text: Adolescents' perceptions of relationship styles. Journal of Youth and Adolescence, 33(4), 293-306. https://doi.org/10.1023/B:JOY0.0000032638.85483.44

Larson, R. W., \& Walker, K. C. (2010). Dilemmas of practice: Challenges to program quality encountered by youth program leaders. American Journal of Community Psychology, 45(3-4), 338-349. https://doi.org/10.1007/s10464-010-9307-z

McQuillin, S. (2018, August 22). Improving mentoring by improving training [Blog post]. https://nationalmentoringresourcecenter.org/index.php/component/k2/item/511-improvingmentoring-by-improving-mentor-training.html 
Journal of Youth Development | http://jyd.pitt.edu/ | Vol. 15 Issue 4 DOI 10.5195/jyd.2020.986 Supporting Volunteerism in Youth Development

Miranda-Díaz, M., Clark-Shim, H., Keller, T. E., \& Spencer, R. (2020). Determinants of motivation for mentoring among adults volunteering to mentor youth. Journal of Youth Development, 15(4), 174-189. https://doi.org/10.5195/jyd.2020.881

Morris, J. (2020). Book review: The 5 languages of appreciation in the workplace. Journal of Youth Development, 15(4), 202-205. https://doi.org/10.5195/jyd.2020.854

Pryce, J. (2012). Mentor attunement: An approach to successful school-based mentoring relationships. Child and Adolescent Social Work Journal, 29(4), 285-305. https://doi.org/10.1007/s10560-012$\underline{0260-6}$

Restler, S., \& Glant, L. (2020). All hands on deck: Building a sustainable volunteer program. Journal of Youth Development, 15(4), 162-173. https://doi.org/10.5195/jyd.2020.877

Spencer, R., Pryce, J., Barry, J., Walsh, J., \& Basualdo-Delmonico, A. (2020). Deconstructing empathy: A qualitative examination of mentor perspective-taking and adaptability in youth mentoring relationships. Children and Youth Services Review, 114, 105043.

https://doi.org/10.1016/j.childyouth.2020.105043

Trzesniewski, K., Horrillo, S. J., \& Lewis, K. M. (2015, October). Evaluation of 4-H Thrive! Helping youth realize their full potential. Presentation at Joint Strategic Initiatives Conference, University of California, Division of Agriculture and Natural Resources.

White, A. J., Sero, R., Scanga, L. H., Cummins, M. M., Lile, J. R., Stott, N. K., \& Leach, J. (2020). "The right tools at the right time": Improving volunteer education and support. Journal of Youth Development, 15(4), 110-144. https://doi.org/10.5195/jyd.2020.878

Worker, S. M., Espinoza, D. M., Kok, C. M., Go, C., \& Miller, J. C. (2020). Volunteer outcomes and impact: The contributions and consequences of volunteering in 4-H. Journal of Youth Development, 15(4), 6-31. https://doi.org/10.5195/jyd.2020.847 